\title{
Variability and Uncertainty Analysis in Value Stream Mapping
}

\author{
Araibi Salahuddin Alaa, A I M Shaiful, Zuraidah Mohd Zain
}

\begin{abstract}
Lately, value stream mapping (VSM) is integrated with tools and techniques that belong to other areas of knowledge such as risk management (RM). It is well known tool in showing the value, value stream and the flow which represents three of lean manufacturing (LM) principles. This integration, gives more benefit in covering two of VSM issues such as considering the variability and uncertainty of production processes. In this paper, a model named variable value stream mapping (V-VSM) that integrates the two was showed, explained and tested. The model helps to generate the VSM in a dynamic way with the identification of current and potential risks. These risks might happen in the future bringing a strong impact on not reaching the main objectives in the defined time and cost. The model has been tested by conducting a case study in food sector. A current state map was built using both models, traditional VSM and V$V S M$. The results showed the effect of variability and uncertainty on the total cycle time $(C T)$ and lead time (LT) values, where the traditional VSM failed to show it by being a static tool. Comparing the results of both models show the differences in presenting the real state of manufacturing environment.
\end{abstract}

Keywords: Monte Carlo simulation, probability distribution, risk management, value stream mapping, variability.

\section{INTRODUCTION}

The terms of 'variability', 'variation', and even 'variety' as they have negative connotations for being associated with unreliability [1]. VSM is a "paper and pencil" based technique which limits both the level of detail such of the variability of process times, inventory and the number of different versions that can be handled. Thus, the lack of detail the dynamic behavior of the production process causes the barriers to effectively apply the improved situations [2]. In [3] insisted on the need to a complementary tool with VSM that can be used to handle uncertainty and create dynamic views of inventory levels, lead-times, and machine utilization for different future state maps. Given the simulation as a good tool for its capability of generating resource requirements and performance statistics whilst remaining flexible to specific organizational details. In [4] combined VSM with discrete-event simulation to define the variability in CT and LT. However, the suggested approach does not show the variability in inventories. In [5] stated "You cannot use a static tool to study a dynamic problem. A static tool gives an optimistic performance assessment. The greater the variability in the system, the greater the error in static analysis." When all the time values involving in VSM

Revised Manuscript Received on September 14, 2019.

Araibi Salahuddin Alaa, School of Manufacturing Engineering, Universiti Malaysia Perlis, Kampus Alam Pauh Putra, 02600 Arau, Perlis, Malaysia. (Email: allaa90@yahoo.com)

A I M Shaiful, School of Manufacturing Engineering, Universiti Malaysia Perlis, Kampus Alam Pauh Putra, 02600 Arau, Perlis, Malaysia. (Email: mshaiful@unimap.edu.my)

Zuraidah Mohd Zain, School of Manufacturing Engineering, Universiti Malaysia Perlis, Kampus Alam Pauh Putra, 02600 Arau, Perlis, Malaysia. (Email: zuraidah@unimap.edu.my.) are associated with some variation. Therefore, in order to establish dynamic state, a simulation based approach need to be carried. Uncertainty leads to introduce variability into process itself, which increases the risk of not meeting objectives [6]. The terms of uncertainty, variability, risk and probability are all words that are commonly related to the predictions of future events or unknown outcomes of past events. The more uncertainty related to a process, the more waste there will be in the process. Thus, the presence of uncertainty stimulates the decision maker to create safety inventory to prevent defects and bad performance.

Although both variability and uncertainty are presented as ranges, it is important to distinguish between them. Uncertainty means we do not know the value (outcome) of some quantity. While, variability refers to the multiple values a quantity has at different locations, times or instances. Both variability and uncertainty represented by probability distribution, which brings a major source of confusion. To be clear, un-certainty depends upon the diction-maker state of information about the probability of the single, true value of the uncertain quantity. Adds on, variability depends on the frequencies of multiple instances of the quantity, derived from observed data [1], [7]. Uncertainties and variability are dynamic and should not be taken for granted. They should be acknowledged, man-aged and minimized to a reasonable degree [8], [9].

Thus, this paper produces an approach of Variable Value Stream Mapping (V-VSM) to analyze the uncertainty and variability and their correlation with all VSM inputs using Monte Carlo simulation. Since the PDCA cycle was approved the successful integration with each VSM [10] and RM [11] in separate. The use of it as a base of integrating both VSM and RM brings more benefits in solving VSM lack of identifying process variability and uncertainty. A case study in food sector was carried to draw the CSM with a comparison with the traditional VSM (T-VSM).

\section{DEFINE THE CONCEPTS OF THE MODEL}

The suggested V-VSM model in this study is under LM particularly VSM tool and risk management (RM) concepts as shown in Fig. 1.

The model used quantitative tools and techniques belong to this two knowledge. The tools and techniques are VSM, probability distribution, Monte Carlo simulation, Risk Probability-Impact Ranking Matrix technique, Risk Register, and finally PDCA as a base of integration. The use of these tools and techniques will be in a way to adopt variability into VSM. This variability represented in CT, LT and work in process (WIP) by giving a range of 3 values

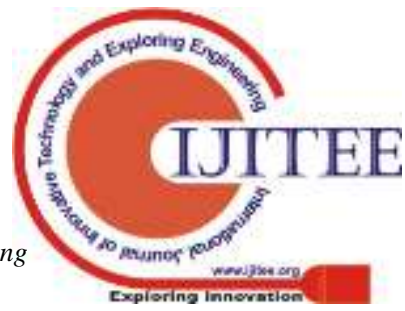


(minimum, most likely and maximum) instead of one value (average of the sampled values) like in the traditional VSM. So, this variability is included inside the drawing maps for both current state map (CSM) and future state map (FSM). As well as, identifying all the potential risks that may occur in the future and the impact of these risks on time, cost and WIP is one of the benefits of this integration.

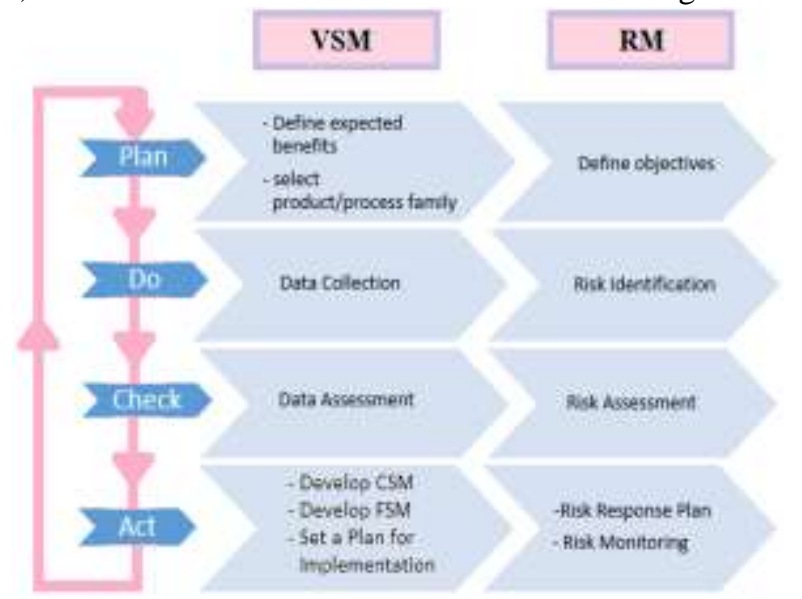

Fig. 1.The integration of VSM and RM into PDCA to develop V-VSM model.

In [12] suggested four main stages when undertaking a VSM study namely: (1) selection of a product family, (2) construction of a current state map, (3), construction of a future state map, and (4) implementation of the future state map. While, risk management consisted of five processes: (1) definition, (2) risk identification, (3) risk assessment, (4) risk response planning, and (5) risk monitoring, control and review. Since the lean approach to manufacturing and RM are aiming to minimize waste and risk continuously, the Deming's PDCA cycle is a good structure to conduct the integration in a systematic, repeatable and continuous cycle of improvement. Thus, Fig. 1 shows how the processes of the traditional VSM and RM concepts are fit together inside the PDCA cycle.

The model concepts in Fig. 1 are arranged in a synchronized way through several steps. benefits and objectives for applying VSM. Such benefit knows the ability of the company towards the customer order, which refers to Takt time. Same for RM, the benefits that encourage the company to apply RM are listed. Such objective is illuminating the current and potential risks. These objectives and benefits are expected to be found in a specific product/process family. Thus, through this phase the most important family of product/process in the company is selected here.

The Do phase is responsible on collecting data for VSM and identifies risks for RM. For VSM, the collected data should be taking by hand while observe the flow of the product moving upstream from costumer to the supplier. While, risks are identified depending on current situation, historical records and potential expectations which are subjected. Each risk has two arguments need to be identified which are probability and impact. The collected inputs data include all the variabilities.

The Check phase is the application of assessment quantitative tools and techniques. For VSM, the collected data need to be analyzed whether they are fit together to be
The Plan phase in Fig. 1 is the defining of the expected

used or randomly chosen. For risk analysis, tools and techniques such risk register, probability distribution are used to identify the range limits of each risk. Using probability distribution helps to narrow the confidence interval. The confidence interval is set by defining the limits of each input variability that the sampled value lies within. The risk analysis works through using Monte Carlo simulation technique. It will work after identifying the input values as probability distribution. A probability distribution which describes the range of possible values for the input is substituted for its original single fixed value. When the simulation is running, these inputs will be used in calculations over and over (each recalculation is iteration) to generate a set of possible values sampled from each input distribution each iteration.

Finally, the Act phase for VSM is the development of the CSM and FSM along with setting a plan on how to implement the FSM. While, RM setting a risk response plan to solve all the identified and assessed risks. As well as, monitoring the progress along the application of risk response plan. Through the monitoring new risks could be found and need to be identified, thus, a new cycle of RM need to be done as a continuous protection and improvement. Same with VSM which is one of LM tool that adopted the continuous improvement characteristic from Deming's PDCA cycle. As a result, all 3 concepts end up having the same goal of continuous improvement.

\section{RESULTS \& DISCUSSION}

The study took place in coffee department belongs to food industry from the time the customer places an order until the delivery of that order. Furthermore, the department staff consisted of three employees. This team participated through the application of the model and contributed as an expert. A company visit was scheduled for seven days in one month.

\section{A Plan Phase}

In choosing the product family, the aim was to focus on the most highly demand products, which are coffee products. The chosen family was highly recommended by the company CEO as well as the employees. The family consists of 6 products of different type of coffee having the same flow of information and materials through the shop's various processes.

Since the coffee product family is highly demand, the expected objectives were enhancing the production flow and find ideas to re-duce/eliminate WIP since the company relays on batching system. The company responding to customer orders is highly restricted to due date. However, in some cases where the customer order quantity is high, it was expected some lateness variability in delivery time. Thus, having a flexible delivery date is one of the objectives the company looking forward. For this case, the customer demand was 1155 sachets of coffee per week. The production processes were in sequence as Weighting, Mixing, Packaging I, Sticking the cover, Packaging II,

Published By:

Blue Eyes Intelligence Engineering 
Sealing, Stumping the expire date, and Boxing. Adding to that, there were 2 inspection processes in between as it showed in the next phase.

\section{B Do Phase}

Data was collected for three working days through direct observation with the aid of a stopwatch and timer. The researcher's style of observation relied heavily on visual information gathering before the use of verbal questioning spatially in the risk data collection part. A total of eight processes were fully documented within the product family. The company works 6 days per week, 2 shifts per day, (4, $4.5,5)$ hours per shift, and 1 hour of break time per day. The risks (10 risks) and their probability, impact, and perspective potential non value added activities (PNVAA) were collected as well. The PNVAA means any occurrences of those risks will bring futuristic wastes as well as additional time and cost, which make the lead time (LT) longer and prevent the delivery on time. Since the data related to risks (probability and impact) are subjective, they were collected with the help of the employees and the company CEO. Each input data was collected has mini-mum, mean, and maximum values to represent the variability in the model.

\section{Check Phase}

This phase contents all the analysis needed for the collected data in the previous phase, starting from fitting the data with a proper distribution. Then, define the all correlations between all input data so the simulation sampling results will not be random. All the risks were ranked according to specific categories were set by the company to specify the risk consequence. The 5 categories were Personnel safety, Public safety, Economic, Corporate image and Environment impact.

The risk consequence results were tested in a heat map to show the most critical risks. The risks were listed in descending order according to their risk ranking as shown in Table I.

Table- I: Risk events/activities

\begin{tabular}{|c|c|l|}
\hline Risky Event/Activities & $\begin{array}{c}\text { Risk } \\
\text { Consequence }\end{array}$ & $\begin{array}{l}\text { Heat Map } \\
\text { Area } \\
\text { Color }\end{array}$ \\
\hline Electricity shutdown & 9 & Yellow \\
\hline $\begin{array}{c}\text { Error in weighting the } \\
\text { ingredients amount }\end{array}$ & 6 & Yellow \\
\hline $\begin{array}{l}\text { Wrong measurement of the } \\
\text { sachet }\end{array}$ & 6 & Yellow \\
\hline $\begin{array}{l}\text { Wrong amount of the } \\
\text { coffee mix inside the sachet }\end{array}$ & 6 & Yellow \\
\hline $\begin{array}{l}\text { Wrong counting the } \\
\text { sachets inside the pack }\end{array}$ & 6 & Yellow \\
\hline Unsealed & 6 & Yellow \\
\hline Visual mistakes & 6 & Yellow \\
\hline Worker absent & 4 & Green \\
\hline Misplacing the sticker & 2 & Green \\
\hline Misplacing the stamp & 2 & Green \\
\hline
\end{tabular}

From Table I, it shows that the "Electricity shutdown" has the highest risk consequence among other risks with a value equals to 9 in the yellow area, followed with 6 risks placed in the same yellow area. The risky events in the yellow area need a regular review and management updates in the $\mathrm{V}$ FSM. Even though, there are 7 risks placed in the yellow area, the "Electricity shutdown" needs more attention to be solved. The rest risks were placed in the green area has little to no impact; however, a continuous review is needed in anticipation of repeating the events and increasing the impact.

For running the simulation, the iteration number was set with 100 iterations using @Risk and Microsoft Excel software. Then by running the simulation, the calculations on sampling process from the input to be processed for specifying the outputs were run for 100 times same as the iteration number. It means each input and output variable has 100 values, yet each value is variable by having minimum, mean, and maximum values. The outputs of the simulation were shown in Table II.

Table- II: Simulation outputs

\begin{tabular}{|c|c|c|c|c|}
\hline Outputs & Graph & Min & Mean & Max \\
\hline $\begin{array}{c}\text { Total } \\
\text { CT }(\mathrm{sec})\end{array}$ & 40 & 42.81 & 2087.115 & 2134.101 \\
\hline $\begin{array}{r}\text { Total } \\
\text { LT }(\mathrm{hr})\end{array}$ & & 3.044 & 143.2414 & 155.0782 \\
\hline \begin{tabular}{l}
\multicolumn{1}{c}{ Time } \\
added to \\
plan \\
$(\mathrm{Sec})$
\end{tabular} & 200 & 0 & 336.9634 & 1774.952 \\
\hline $\begin{array}{l}\text { Costs } \\
\text { added to } \\
\text { plan }(\$)\end{array}$ & 10 & 0 & 19.16535 & 79.53492 \\
\hline
\end{tabular}

Table II shows the identified outputs of the simulation results. It also shows each output's graph and variable values. The minimum values of both time added to plan and cost added to plan are equal to zero. By looking at the histogram graph for both of them, it showed that the highest bar is placed in the zero value. It means that during the simulation run few samples were selected between the 100 iteration giving the mean and maximum values as shown in the Table II. While, the rest of sampled values (which has the largest part of the total samples) were located outside the identified ranges for each input and as a result of that a zero value was given. All the outputs' histograms were shown clearly in Fig. 2-5. The total CT in Fig. 2 shows the highest bar in the histogram is in the middle where the mean value. It means that the largest number of sampling process was around the mean value. Same goes to the total LT where the largest bar is located around the mean value. 


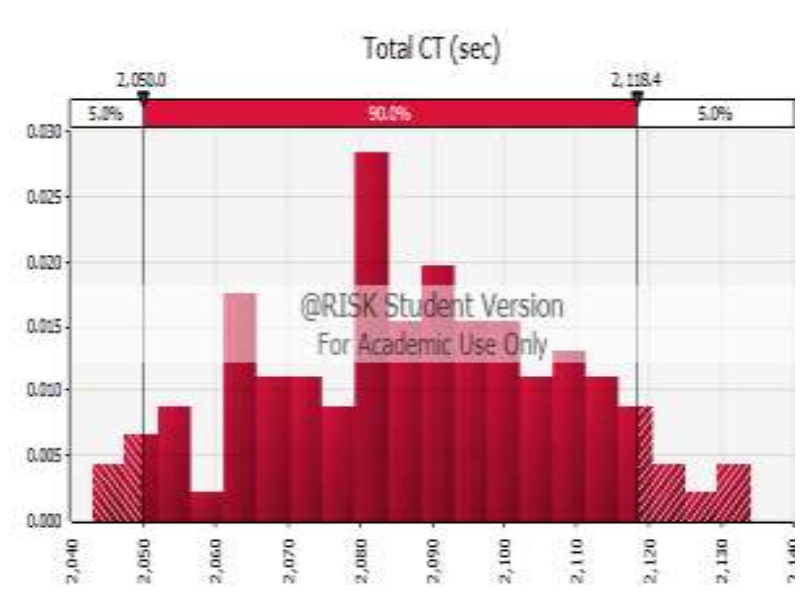

Fig. 2.Monte Carlo simulation results for total CT.

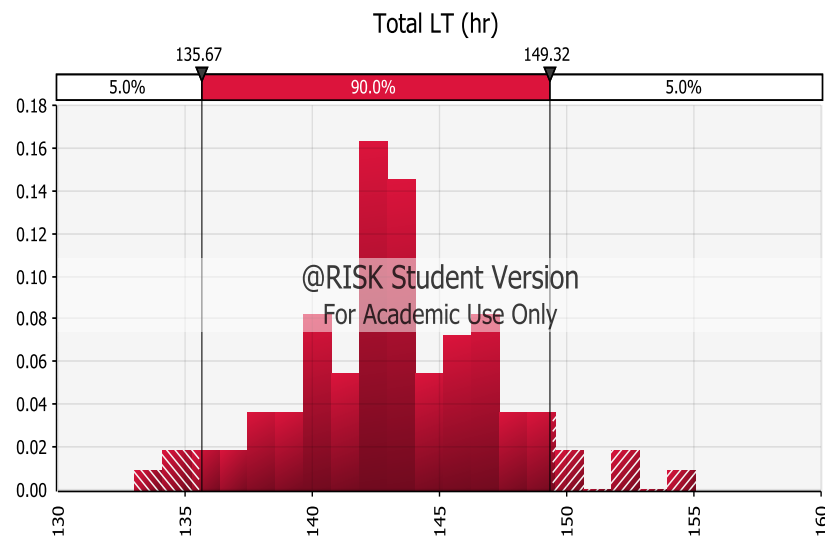

Fig. 3.Monte Carlo simulation results for total LT.

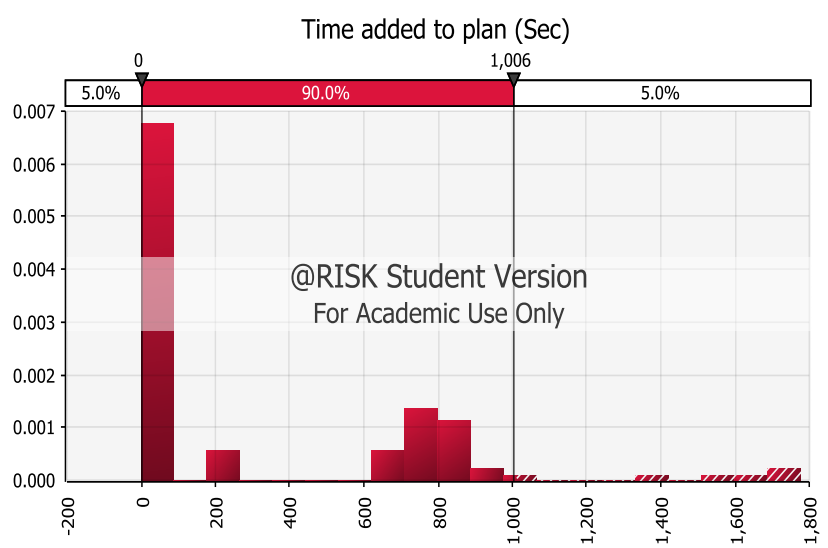

Fig. 4.Monte Carlo simulation results for time added to plan (sec).

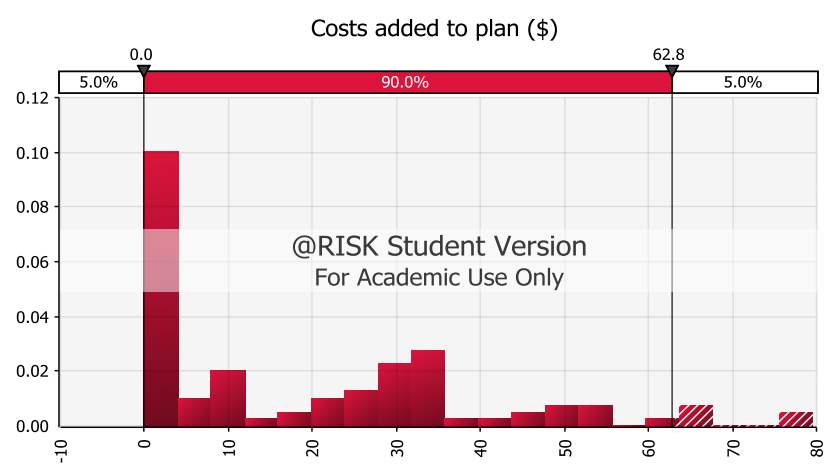

Fig. 5.Monte Carlo simulation results for cost added to Plan (\$).

The simulation results were compared to the traditional VSM (T-VSM) in Table III. Having this comparison gives a comprehensive over-view of the developed model's results and the percentage of differences with the traditional results. With this, the highest anticipated risks can be considered in the development of the future state map.

From Table III, it shows the variability in the model's outputs by having a range of 3 values of each output unlike the T-VSM that deals with one value considered as the average. The maximum and minimum limitation ranges of variability were expressed by a giving percent-age comparing to the values of T-VSM. It was observed that the mean value of the V-VSM is less than the value of T-VSM because the T-VSM takes the average of all values, while VVSM processing the collected data with fitting it into distribution to make sure the accuracy of the collected data and to know what distribution will fit the overall data shape. Data correlation is considered between inputs by identifying the positive and negative relationships that will make them connected to any impact of increment or decreasing. Running the simulation with these constrains and correlations bring an additional accuracy to the results of the simulation in V-VSM comparing to T-VSM. Moreover, Table III shows the added time and cost as an impact if the identified risks happened specially the highlighted risks by risk ranking matrix. While, the last column shows the difference in percentage to the T-VSM.

\section{Act Phase}

The results of the Monte Carlo simulation were used to draw the current situation of the company as shown in Fig. 6. The map showed the T-VSM and V-VSM drawing style as a comparison of the way in presenting the inputs and outputs using both models.

Under each process of V-VSM model the CT and risks were varied in the information part. While, in the time part the way of presenting the times (VA and NVA) were presented differently than the traditional way. A curvy line presented the times showing the flexibility and variability in data points as shown in Fig. 6. The total CT, LT and risks time added were calculated in the information box. The VCSM shows how the data inputs are varying, which reflects a true image of the variable manufacturing environment 
Table- III: Results summary

\begin{tabular}{|c|c|c|c|c|}
\hline Outputs & T-CSM & & V-CSM & $\%$ Changes from the T-CSM \\
\hline \multirow{3}{*}{$\mathrm{CT}(\mathrm{sec})$} & \multirow{3}{*}{2092.99} & $\min$ & 2042.814 & $\begin{array}{l}\text { If the minimum limits applied, it will reduce }-2.4 \% \text { sec of the total CT than the } \\
\text { traditional one, which is equal to } 42 \mathrm{sec} \text {. }\end{array}$ \\
\hline & & mean & 2087.115 & The mean of CT is reduced by $-0.2 \%$ sec equal to $6 \mathrm{sec}$ than the traditional CT. \\
\hline & & $\max$ & 2134.101 & $\begin{array}{l}+2 \% \text { sec will be the added to the total traditional CT if it is equal to the maximum limits } \\
\text { of CT. which is equal to } 40 \mathrm{sec}\end{array}$ \\
\hline \multirow{3}{*}{ LT (hr) } & \multirow{3}{*}{143.6} & $\min$ & 133.0441 & $-7 \% \mathrm{hr}$ which is a reduction of almost one day working (one day working $=8 \mathrm{hr}$ ). \\
\hline & & mean & 143.2414 & $-0.2 \% \mathrm{hr}$ is the reduction in time which is equal to $17 \mathrm{~min}$ of the traditional total LT. \\
\hline & & $\max$ & 155.0782 & $\begin{array}{l}+7 \% \mathrm{hr} \text { are added to the traditional LT which is equal to almost one day working (one } \\
\text { day working }=8 \mathrm{hr} \text { ). }\end{array}$ \\
\hline \multirow{3}{*}{$\begin{array}{l}\text { Added delay } \\
\qquad(\sec )\end{array}$} & \multirow{3}{*}{-} & $\min$ & 0 & There is no impact to the minimum value of the risks occurrence. \\
\hline & & mean & 336.9634 & $\begin{array}{l}\text { Another } 6 \text { minutes will be added to the total LT if no action will be taken to reduce the } \\
\text { most critical risks }\end{array}$ \\
\hline & & $\max$ & 1774.952 & $\begin{array}{l}30 \text { minutes will be added to the total LT if no action will be taken to reduce the most } \\
\text { critical risks. }\end{array}$ \\
\hline \multirow{3}{*}{$\begin{array}{l}\text { Added Cost } \\
\qquad(\$)\end{array}$} & \multirow{3}{*}{ - } & $\min$ & 0 & There is no impact to the minimum value of the risks occurrence. \\
\hline & & mean & 19.16535 & $\begin{array}{l}\text { Added cost as an impact to the occurrence of the critical risks around the mean of their } \\
\text { time. }\end{array}$ \\
\hline & & $\max$ & 79.53492 & $\begin{array}{l}\text { More cost added as an impact to the occurrence of the critical risks around the max of } \\
\text { their time. }\end{array}$ \\
\hline
\end{tabular}

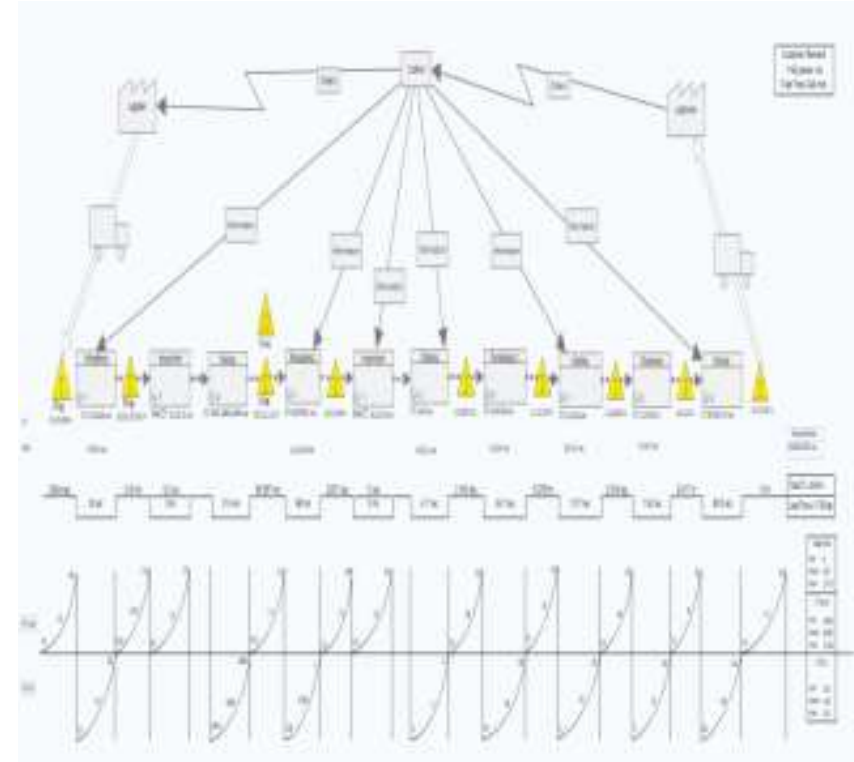

Fig. 6.V-CST vs. T-CSM

\section{CONCLUSION}

The VSM displays a picture of the manufacturing process in a specific day. Therefore, it tends to vary depending on the state in which the factory is. If the variation in production process neglected during the preparation of CSM, the FSM will be inaccurate. It can effect on operating parameters such as $\mathrm{CT}$, as well as, measures of performance such as Takt time of the manufacturing system. Thus, this paper presents an advance VSM named V-VSM with a complementary tool using RM processes. The suggested model was tested in a case study in the food sector. The results showed the ability of the model in specifying the ranges of variability in production processes as well as the potential risks and potential wastes (PNVAA). As well as, the model can show the correlated input data so the Monte Carlo simulation results are not randomly chosen. A compression between T-VSM and V-VSM was shown through building the CSM.

\section{ACKNOWLEDGMENT}

The authors would like to thank the Ministry of Higher Education of Malaysia and the Research Management Center and Innovation, Universiti Malaysia Perlis for awarding the research grant under the Fundamental Research Grant Scheme (FRGS/1/2018/TK07/UNIMAP/02/2).

\section{REFERENCES}

1. W. Cowper, The task: Book 3. The garden. https://ebooks.adelaide.edu.au/c/cowper/william/task/boo k3.html.

2. Y. H. Lian and H. Van Landeghem, "An application of simulation and value stream mapping in lean manufacturing," 14th Eur. Simul. Symp., 2002, pp. 1-8.

3. F. A. Abdulmalek and J. Rajgopal, "Analyzing the benefits of lean manufacturing and value stream mapping via simulation: A process sector case study," Int. J. Prod. Econ., 107(1), 2007, pp. 223-236.

4. Y. H. Lian and H. Van Landeghem, "Analysing the effects of Lean manufacturing using a value stream mapping-based simulation generator," Int. J. Prod. Res., 45(13), 2007, pp. 3037-3058.

5. S. Kannan, Y. Li, N. Ahmed, and Z. El-Akkad, "Developing a Maintenance Value Stream map," Inst. Ind. Eng. Tech. Soc. Div. Lean Conf., 2007, pp. 1-8.

6. S. Abdoli, S. Kara, and B. Kornfeld, "Application of dynamic value stream mapping in warehousing context," Mod. Appl. Sci., 11(1), 2017, pp. 1913-1852.

7. S. Begg, R. Bratvold, and J. Campbell, "The value of flexibility in managing uncertainty in oil and gas investments," SPE Annual Technical Conference and Exhibition, 2002, pp. 1-10.

8. W. Guo, Development of a framework for preliminary risk analysis in transportation projects. Master thesis, Massachusetts: Worcester Polytechnic Institute, 2004.

9. I. D. Tommelein and M. Weissenberger, "More just-intime: Location of buffers in structural steel supply and construction processes," Proceedings International Group for Lean Construction, 1999, pp. 109-120.

10. J. A. Garza-Reyes, J. Torres Romero, K. Govindan, A. Cherrafi, and U. Ramanathan, "A PDCA-based approach to Environmental Value Stream Mapping (E-VSM), J. 
Clean. Prod., 180, 2018, pp. 335-348.

11. M. M. Ren, N. Ling, X. Wei, and S. H. Fan, "The application of PDCA cycle management in project management," IEEE International Conference on Computer Science and Applications, 2017, pp. 268-272.

12. M. Rother and J. Shook, Learning to See: Value Stream Mapping to Add Value and Eliminate Muda. Massachusetts: Lean Enterprise Institute, 1998.

\section{AUTHORS PROFILE}

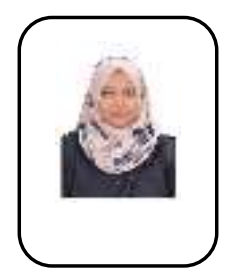

Alaa Salahuddin Araibi is a researcher in lean manufacturing field. Her under-graduated and Ms.C degrees were specialized in Industrial Engineering at university of Technology (Baghdad/Iraq). she is pursuing her $\mathrm{PhD}$ Degree in lean manufacturing, specially value stream mapping at School of Manufacturing Engineering, Universiti Malaysia Perlis (UniMAP), Malaysia

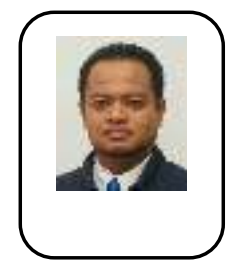

Mohamad Shaiful Ashrul Ishak ia a lecturer tha holds a Bachelor Degree in Mechanical-Aero Engineering in 2001; Master in Mechanical Engineering (Gas Turbine Combustion) in 2005 and $\mathrm{PhD}$ in Combustion in 2015 from UTM, Malaysia. He has vast experience in Mechanical Engineering as academician with more than 40 publications as well as professional consultant in the field of Mechanical and Manufacturing. He also is a highly respectable and reputable professional in the field of Mechanical and registered Professional Engineer with Board of Engineer Malaysia (BEM).

Zuraidah binti Mohd Zain is a Professor in Manufacturing Engineering School, Universiti Malaysia Perlis (UniMAP), in Malaysia. She had her Ph.D. in Industrial Engineering University of Liverpool, UK. While her B.Sc. was in Materials Sc. and Engineering, University of Florida, USA. 